\title{
The effect of vitamin D add-on therapy on the improvement of quality of life and clinical symptoms of patients with chronic spontaneous urticaria
}

\author{
Seyed Hesamedin Nabavizadeh, ${ }^{1,2}$ Soheila Alyasin, ${ }^{1,2}$ Hossein Esmaeilzadeh, ${ }^{1,2}$ Fereshteh Mosavat, ${ }^{2}$ Narjes Ebrahimi ${ }^{1}$
}

\begin{abstract}
Background: Chronic urticaria is a common distressing allergic skin disorder. Immune dysregulation, histamine release and mast cell degranulation are suggested as its underlying mechanisms.

Objective: Add-on therapy of vitamin D was evaluated in patients with chronic spontaneous urticaria to determine the quality of life and urticaria severity score.

Methods: In a prospective, double-blinded study, 80 participants with chronic spontaneous urticaria were randomized to low (4200 IU/week, group 1) and high (28,000 IU/week, group 2) vitamin D3 supplementation groups for 12 weeks. Demographic data; quality of life, urticaria severity and medication scores; 25-hydroxyvitamin D and anti-thyroid peroxidase antibody levels; and autologous serum skin test data were collected.

Results: Both groups showed significantly reduced total urticaria severity score; decrement in group 2 score was significant compared to group 1 at week $6(P=0.010)$. Quality of life score was also significantly reduced; decrement in group 2 score was significant compared to group 1 at both weeks $6(P=0.005)$ and $12(P=0.007)$. 25-hydroxyvitamin D levels were elevated significantly over the course of 12 weeks in both groups; however, the elevation in group 2 was significantly higher than group 1 at week $12(P=0.002)$. Medication score was significantly reduced, with no significant difference between groups. No association was observed between positive autologous serum skin test, angioedema and high level of Anti thyroperoxidase antibody with positive response to vitamin D.
\end{abstract}

Conclusion: Add-on therapy with vitamin D (28,000 IU/week) can be considered as a safe and potentially beneficial treatment in patients with chronic spontaneous urticaria.

Key words: Add-on Therapy, Chronic Urticaria, Clinical symptoms, Quality of life, Vitamin D

From:

${ }^{1}$ Allergy Research Center, Shiraz University of Medical Sciences,

Shiraz, Iran

${ }^{2}$ Department of Allergy and Clinical Immunology, Namazi Hospital, Shiraz University of Medical Sciences, Shiraz, Iran

Corresponding author:

1.Hossein Esmaeilzadeh

Allergy Research Center, Mohammad Rasool Allah Research Tower,

Khalili Street, Shiraz, Iran, 719335899

E-mail: esmailzadeh_ho@yahoo.com

2.Fereshteh Mosavat

Department of Allergy and Clinical Immunology, Namazi hospital, Shiraz University of Medical Sciences, Shiraz, Iran, 719335899

E-mail: mosavatfereshteh@yahoo.com

Abbreviations:

- ACD Allergic contact dermatitis

- ANA Antinuclear antibody

- anti TPO Anti thyroid peroxidase
Abbreviations (Continued)

- AD Atopic dermatitis

- ASST Autologous serum skin test

- CU Chronic urticaria

- CU-Q $\mathrm{Q}_{2} \mathrm{oL}$ Chronic urticaria quality of life

- DLQI Dermatology life quality index

- NSAIDs Nonsteroidal anti-inflammatory drugs

- TSH Thyroid stimulating hormone

- UAS Urticaria activity score

- USS Urticaria severity score

- 25(OH)D 25 hydroxy vitamin D

\section{Introduction}

Chronic urticaria (CU) is defined as daily presentation of wheals, angioedema or both that continuous for six weeks or more. ${ }^{1}$ It was reported that $10-20 \%$ of the general population experience at least one episode of urticaria and $1 \%$ of the general population experience $\mathrm{CU} .^{2} \mathrm{CU}$ is presented as 
urticarial wheals in $50 \%$ of the patients; $10 \%$ of the patients experience angioedema alone and wheal and angioedema coexist in $40 \%$ of the patients. ${ }^{3}$ Two types of CU are defined: chronic inducible urticaria and chronic spontaneous urticaria. The latter is defined as spontaneous presentation of wheal and/or angioedema without any specific trigger. ${ }^{2}$

The pathogenesis of CU has not been exactly defined. Increasing evidence suggest the role of auto immunity in CU pathogenesis. ${ }^{4}$ Autologous serum skin test (ASST) is applied as a simple and inexpensive in vivo screening test that determine histamine releasing factors in serum, including histamine releasing auto antibodies in $\mathrm{CU} .{ }^{5,6} \operatorname{IgG}$ thyroid auto antibodies (anti thyroid peroxidase (anti TPO) antibodies) were observed in $30 \%$ of CU cases, while the incidence of thyroid auto antibodies in the general population is $5-10 \%$. The activation of 'autoallergic' mast cells through anti TPO was reported recently, while functional IgG antibodies against IgE or FceR1 were also observed. ${ }^{6,7}$

Based on EAACI/GA ${ }^{2}$ LEN/EDF/WAO Guideline for urticarial management, second generation $\mathrm{H} 1$ antihistamines are the first line pharmacological therapy of CU and up dosing is recommended in case that clinical presentations persist. Omalizumab and cyclosporine are recommended as $3^{\text {rd }}$ and $4^{\text {th }}$ line treatment. ${ }^{8}$ Addition of Montelukast and $\mathrm{H} 2$ antihistamines are also suggested. ${ }^{9,10}$

There are promising clinical observations that reported the association of vitamin D with allergic diseases. ${ }^{11-13}$ Some studies were designed to find out the role of vitamin $\mathrm{D}$ in atopic dermatitis (AD), ${ }^{14,15}$ allergic contact dermatitis (ACD) and $\mathrm{CU}^{16}$ due to immune dysregulation mechanisms, involved in these diseases. Correlation between vitamin $\mathrm{D}$ deficiency with $\mathrm{AD}$ and ACD severity, was observed in previous reports. ${ }^{17}$

Some studies revealed the role of vitamin D in CD $141^{+}$ cells' activation that is engaged in T-reg activation and inflammation inhibition through IL10 release. These mechanisms might help to understand immunomodulatory effects of vitamin $\mathrm{D},{ }^{18}$ as an add-on therapy for CU treatment, due to its immunomodulatory effects. ${ }^{19}$ In previous studies, the lower levels of vitamin D were reported in CU patients. ${ }^{17,20,21}$ Vitamin $\mathrm{D}$ add-on therapy resulted in reduced severity of clinical symptoms $^{22}$ and improved quality of life. ${ }^{23,24}$ However, studies are few and there is inadequate evidence to support the administration of vitamin D supplementation in CU patients. ${ }^{17}$

The present study was designed to assess the effect of low (4200 IU) and high dose (28000 IU) of vitamin D add-on therapy, applied once a week, on the clinical symptoms and quality of life of CU patients in Shiraz (southwest of Iran). The results were evaluated based on urticaria severity score (USS) and chronic urticaria quality of life $\left(\mathrm{CU}-\mathrm{Q}_{2} \mathrm{OL}\right)$ questionnaires, considering the presence of angioedema, anti TPO antibody and ASST test positivity.

\section{Methods \\ Study design}

This is a randomized double blind clinical trial study, conducted 2016-18 in a tertiary referral center (Emam Reza Allergy Clinic affiliated with Shiraz University of Medical Sciences). Approved by local Ethics Committee of Shiraz University of
Medical Sciences, this study was registered in ClinicalTrials.gov identifier (NCT number: NCT02873364).

Sample size was determined using medCalc software and randomization was conducted with permuted block randomization method, with block size of four.

\section{Inclusion criteria}

Patients ( $\geq 12$ years old) who fulfilled the CU criteria, diagnosed by allergy and immunology specialists were recruited: patients with the history of CU and/or angioedema, presented most of the week days, that had continued longer than 6 weeks, were included. Written Informed consent was obtained from each participant.

\section{Exclusion criteria}

Patients with one or more of the following criteria were excluded:

Chronic inducible urticaria, hereditary/acquired angioedema, urticarial vasculitis, sarcoidosis, primary hyper paratyroidism, anaphylaxis, auto inflammatory syndromes, hyper calcemia (serum Ca level $>10.3 \mathrm{mg} / \mathrm{dL}$ and spot urine Ca level $\geq 30$ $\mathrm{mg} / \mathrm{dL}), 25(\mathrm{OH}) \mathrm{D} \geq 200 \mathrm{ng} / \mathrm{mL}$, renal failure (GFR $<50 \mathrm{~mL} /$ $\mathrm{min} / 1.73 \mathrm{~m}^{2}$ ), renal lithiasis, malignancy, pregnancy, lactation and granulomatous disease.

Nonsteroidal anti-inflammatory drugs (NSAIDs) and alcohol, as CU triggers, were prohibited throughout the study.

\section{Intervention}

Total of 80 patients were divided into two equal groups. Group 1 received low dose (4200 IU/week) and group 2 received higher doses (28000 IU/week) of vitamin D (as vitamin $\mathrm{D}_{3}$ pearls), weekly, for 12 weeks. Trial profile is shown in Figure 1. Doses of vitamin D were selected based on the minimum and maximum safe dose for patients aged $\geq 12$ years. ${ }^{25}$

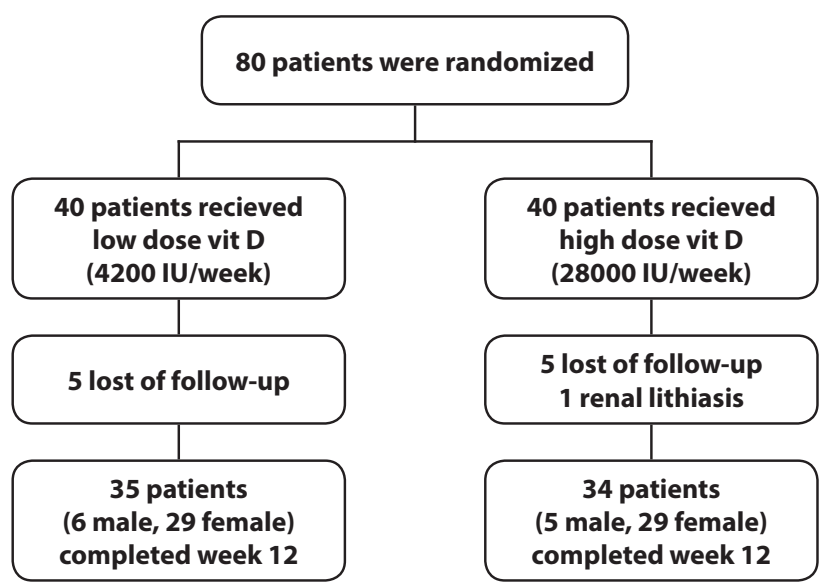

Figure 1. Trial profile (randomized double blind). Total number of the enrolled patients, number of the patients in each study group and number of the patients who completed the study are presented.

\section{Baseline medication and medication score}

Based on previous studies and guide lines, ${ }^{9,26}$ the baseline treatment protocol was designed as follows: 1) cetirizine: 10 $\mathrm{mg} /$ day up to $40 \mathrm{mg} /$ day. 2) Montelukast: $5 \mathrm{mg} /$ day (12-14 year 
old patients) and $10 \mathrm{mg} /$ day (patients $>14$ years old). 3) Ranitidine: $4-5 \mathrm{mg} / \mathrm{kg} /$ day (12-14 year old patients) and $300 \mathrm{mg} /$ day (patients $>14$ years old). The dose of cetirizine was adjusted based on the USS. Short course of prednisolone therapy (maximum four days) was applied as rescue therapy. Patients received allergy medications for at least one month and medication score was calculated at this primary endpoint. Then vitamin $\mathrm{D}$ was added to the medication regimen and medication score was noted at weeks 6 and 12 .

To calculate the medication score, points 2 and 8 were assigned for regular dose and 4 fold doses of antihistamines. Point 2, 6 and 8 were assigned for montelukast, hydroxychloroquine and cyclosporine $(3 \mathrm{mg} / \mathrm{Kg})$, respectively. Points 5,10 and 15 were assigned for $<11 \mathrm{mg}, 11-25 \mathrm{mg}$ and $>25 \mathrm{mg}$ of prednisolone, respectively.

\section{Data collection}

Demographic data and medical history were collected in the prepared data sheets. Baseline characteristics such as: age, gender, body mass index (BMI), ethnicity, educational level, duration of hives, vitamin D level at enrollment, atopy, angioedema, ASST, vitamin D supplementation prior to the study, smoking, alcohol consumption, NSAID exacerbation, thyroid diseases, anti-nuclear antibody (ANA), and anti TPO positive test were recorded.

\section{Questionnaires}

The effectiveness of the treatment was evaluated based on the translated USS questionnaire ${ }^{27}$ and clinical symptoms were scored from 0 to 93 . This questionnaire was applied since it is validated in Persian language. Higher USS scores indicate more severity of the disease. QoL was also assessed based on the translated and validated $\mathrm{CU}-\mathrm{Q}_{2} \mathrm{oL}$ questionnaire. ${ }^{28}$ Higher QoL scores indicate lower quality of life. Questionnaires were filled at baseline, weeks 6 and 12 .

\section{Lab data}

Blood samples were collected to assess serum levels of: albumin, $\mathrm{Ca}, \mathrm{P}$, thyroid stimulating hormone (TSH), antinuclear antibody (ANA), anti TPO, free thyroxin and renal function, at patient enrollment. Serum level of 25-hydroxyvitamin D $(25(\mathrm{OH}) \mathrm{D})$ was recorded to assess vitamin $\mathrm{D}$ level at three time points: at baseline, weeks 6 and 12. 25(OH)D level $<20$ $\mathrm{ng} / \mathrm{mL}, 20-30 \mathrm{ng} / \mathrm{mL}$ and $\geq 30 \mathrm{ng} / \mathrm{mL}$ were considered as deficient, insufficient and sufficient, respectively. ${ }^{29}$

Spot urine was analyzed to determine urine Ca level in three time points: at enrollment, weeks 6 and 12 .

\section{ASST test}

ASST test was conducted as reported by Sabroe et al. ${ }^{30}$ Intradermal injection of normal saline and prick test of histamine $(10 \mathrm{mg} / \mathrm{mL})$ were considered as negative and positive controls. Following the intradermal injection of fresh autologous serum $(0.05 \mathrm{~mL})$, the red wheal diameter $\geq 15 \mathrm{~mm}$ (compared to negative control) was considered as positive.

\section{Statistical analyzes}

SPSS software was used to analyze data. Repeated measure ANOVA (RMANOVA) was applied to compare the difference in variables over time and between groups ( $P \leq 0.05$ was considered to be statistically significant). Since RMANOVA results showed minor differences, comparison between groups was performed in detail with student t-test, considering adjusted $a$ $(\alpha=0.017)$. To observe the differences within one group over the time, RMANOVA and Friedman's test were used for parametric (QoL and USS scores) and non-parametric data (25( $\mathrm{OH})$ level and medication score). To compare two paired groups (comparison of time points within one group), paired sample t-test and Wilcoxon signed rank analyzes were applied for parametric and non-parametric data. Baseline parameters were compared between groups with independent t-test and Mann-Whitney U-test, for parametric and non-parametric data; and $P<0.05$ was considered as significant. Based on the analysis of questionnaires and the difference of vitamin D level between the groups that received high (28000 IU/week) and low dose (4200 IU/week) of vitamin D, the results of high dose group (group 2) was compared with low dose group (group 1), as the control group.

\section{Results}

In this study, 80 patients were recruited based on the aforementioned criteria and 69 patients were followed. In group 1, five patients did not comply with their medication order or follow-up. In group 2, five patients were excluded due to personal reasons and one patient due to renal lithiasis. Hence, in group 1, 35 patients ( 6 male and 29 female) with the mean age of $40.02(17-75)$ years old and in group 2, 34 patients (5 male and 29 female) (Figure 1) with the mean age of 39.94 (18-76) years old were studied. The mean course of the disease was 6.62 and 4.24 years for groups 1 and 2 .

There was no significant difference in terms of the base line characteristics (age, gender, BMI, ethnicity, duration of hives, vitamin D level at baseline, atopy, angioedema, ASST) in groups 1 and 2, except for the number of patients with thyroid dysfunction, which was higher in group $2(P=0.040)$ (Table 1).

Table 1. Baseline criteria of CU patients in this study

\begin{tabular}{|c|c|c|c|}
\hline \multirow{2}{*}{ Baseline characteristics } & \multicolumn{2}{|c|}{ Vitamin $\mathrm{D}_{3}$ treatment group } & \multirow{2}{*}{$P$-value } \\
\hline & $4200 \mathrm{IU} /$ week $(\mathrm{N}=35)$ & 28000 IU/week ( $N=34)$ & \\
\hline Age (year) & $40.02(17-75)$ & $39.94(18-76)$ & 0.978 \\
\hline Male sex & $6(17.14 \%)$ & $5(14.70 \%)$ & 0.521 \\
\hline Female sex & $29(82.85 \%)$ & $29(85.29 \%)$ & \\
\hline Body mass index $\left(\mathrm{Kg} / \mathrm{m}^{2}\right)$ & $26.87 \pm 3.8$ & $27.04 \pm 4.3$ & 0.871 \\
\hline White Asian race & $35(100 \%)$ & $34(100 \%)$ & - \\
\hline
\end{tabular}


Table 1. Baseline criteria of CU patients in this study

\begin{tabular}{|c|c|c|c|}
\hline \multirow{2}{*}{ Baseline characteristics } & \multicolumn{2}{|c|}{ Vitamin $\mathrm{D}_{3}$ treatment group } & \multirow{2}{*}{$P$-value } \\
\hline & $4200 \mathrm{IU} /$ week $(\mathrm{N}=35)$ & 28000 IU/week $(\mathrm{N}=34)$ & \\
\hline \multicolumn{4}{|l|}{ The highest educational level } \\
\hline Elementary school & $2(5.88 \%)$ & $10(28.57 \%)$ & 0.051 \\
\hline Secondary school & $9(26.47 \%)$ & $7(20.00 \%)$ & \\
\hline High school & $16(47.05 \%)$ & $9(25.71 \%)$ & \\
\hline College or higher & $7(20.58 \%)$ & $9(25.71 \%)$ & \\
\hline $\begin{array}{l}\text { Vitamin D supplementation prior } \\
\text { to the study }\end{array}$ & $4(11.42 \%)$ & $2(5.88 \%)$ & 0.351 \\
\hline \multicolumn{4}{|l|}{ 25(OH)D level } \\
\hline Deficient $(<20 \mathrm{ng} / \mathrm{mL})$ & $21(60.00 \%)$ & $24(70.58 \%)$ & 0.639 \\
\hline Insufficient (20-30 ng/mL) & $9(25.71 \%)$ & $6(17.64 \%)$ & 0.637 \\
\hline Sufficient $(\geq 30 \mathrm{ng} / \mathrm{mL}$ ) & $5(14.28 \%)$ & $4(11.76 \%)$ & 0.449 \\
\hline Alcohol consumption & $1(2.94 \%)$ & $2(5.71 \%)$ & 0.511 \\
\hline Smoker & $1(2.94 \%)$ & $2(5.71 \%)$ & 0.511 \\
\hline NSAID exacerbation symptom & $3(8.82 \%)$ & $7(20.00 \%)$ & 0.165 \\
\hline Atopy & $19(54.28 \%)$ & $20(58.82 \%)$ & 0.446 \\
\hline Angioedema & $25(71.42 \%)$ & $22(64.70 \%)$ & 0.367 \\
\hline Positive ANA ( $>1: 40$ titer) & $3(8.82 \%)$ & $0(0 \%)$ & 0.114 \\
\hline Positive anti TPO (> $34 \mathrm{IU} / \mathrm{mL})$ & $7(20.00 \%)$ & $9(26.47 \%)$ & 0.363 \\
\hline Thyroid disease & $5(14.28 \%)$ & $12(35.29 \%)$ & 0.040 \\
\hline Taking Levothyroxine & $8(22.85 \%)$ & $12(35.29 \%)$ & 0.191 \\
\hline Positive aoutologus serum skin test & $12(34.28 \%)$ & $14(41.17 \%)$ & 0.339 \\
\hline
\end{tabular}

${ }^{*}$ Data are presented as mean (range) for age, mean \pm SD for body mass index and number (\%) for other characteristics.

${ }^{*}$ Abbreviations: IU, international unit; 25(OH)D, 25-hydroxyvitamin D; NSAID, non-steroidal anti-inflammatory drugs; ANA, anti-nuclear antibody; anti TPO, anti thyroperoxidase. Baseline parameters were compared between groups with independent $\mathrm{t}$-test and Mann-Whitney U-test, for parametric and non-parametric data. $P<0.05$ was considered as significant

\section{Questionnaires}

At the beginning of the study, mean $\mathrm{CU}-\mathrm{Q}_{2} \mathrm{OL}$ total scores were not statistically different between groups 1 and 2 (Figure 2A). At the end of the study, total CU- $\mathrm{Q}_{2} \mathrm{OL}$ scores were significantly reduced in each group $(P<0.0001)$ : $30.64 \%$ and $42.99 \%$ reduction in groups 1 and 2 . In both groups, the observed decrement in $\mathrm{CU}-\mathrm{Q}_{2} \mathrm{OL}$ score was significant at weeks 6 and 12, compared to baseline $(P<0.0001)$. The decrement at week 12 was also significant compared to week 6 in low dose $(P=0.006)$ and high dose groups $(P=0.016)$. Comparing low and high dose groups, a significant reduction in mean $\mathrm{CU}-\mathrm{Q}_{2} \mathrm{oL}$ score was observed in high dose group at weeks $6(P=0.005)$ and 12 $(P=0.007)$, compared to low dose group.

As shown in Figure 2B, at the beginning of the study, the mean USS total scores were not statistically different between group 1 and 2. At the end of the study, USS means total score was significantly reduced in each group $(P<0.0001): 50.05 \%$ and $67.58 \%$ reduction in group 1 and 2 . Significant difference was observed between baseline with weeks 6 and 12 in both groups $(P<0.0001)$. The difference of week 6 and 12 was significant in group $1(P<0.0001)$; however, this difference was not significant in group 2. Comparing two groups of the study, the mean USS score was significantly decreased in group 2 at week $6(P=0.010)$; however, no significant difference was observed at week 12 between groups 1 and 2 .

\section{Medication score for $\mathrm{CU}$}

At the baseline, the medication score was not statistically different in groups 1 and 2. The medication score was significantly reduced to 3.37 and 5.17 in groups 1 and $2(P<0.0001)$ throughout the study. In both groups the decrement in medication score was statistically significant at both weeks 6 and 12 , compared to baseline $(P \leq 0.0001)$; and at week 12 , compared to week 6 , as well $(P \leq 0.0001$ and $P=0.004$ for groups 1 and 2). However, no significant difference in medication score was observed between groups 1 and 2. Data are presented in Figure 2C. 


\section{A}

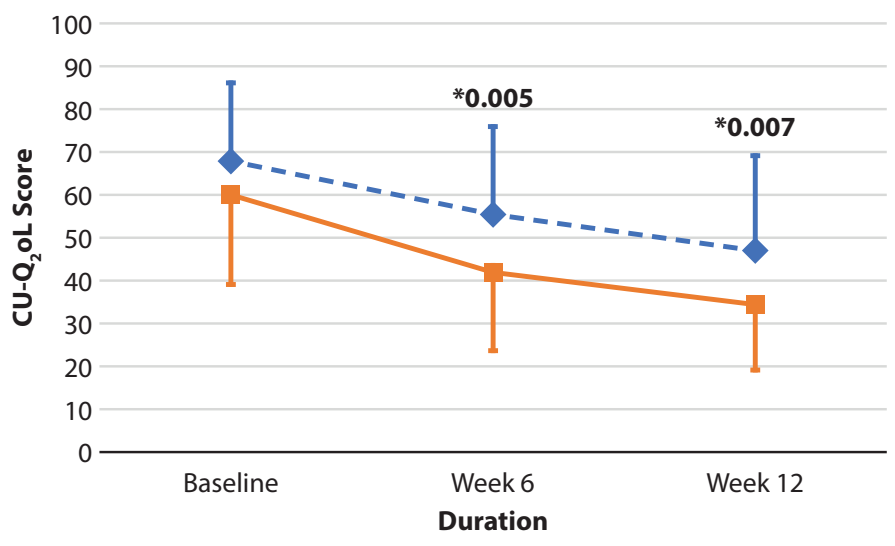

$-\diamond-$ Group 1 (4200 IU/Week) $\quad \longrightarrow$ Group 2 (28000 IU/Week)

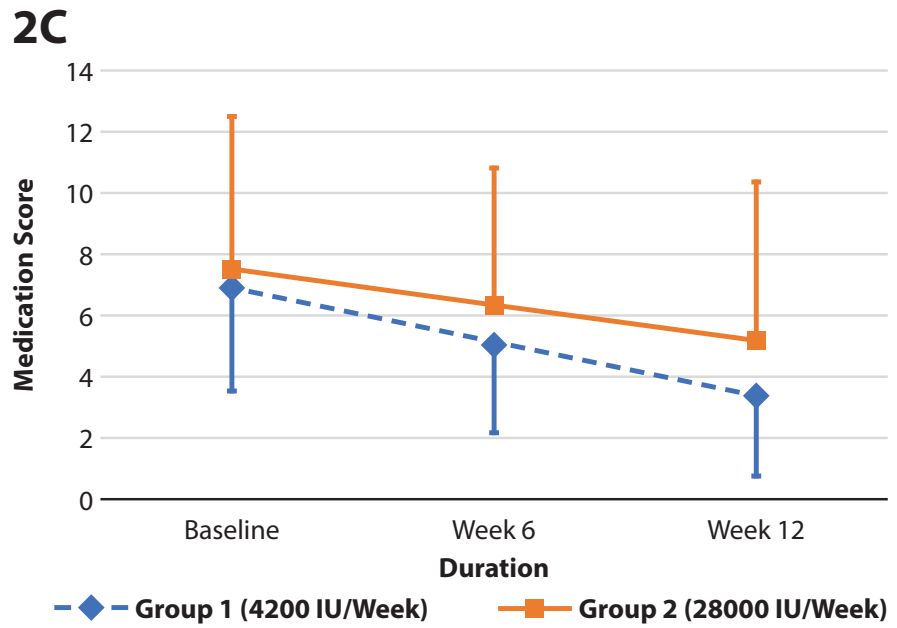

2B

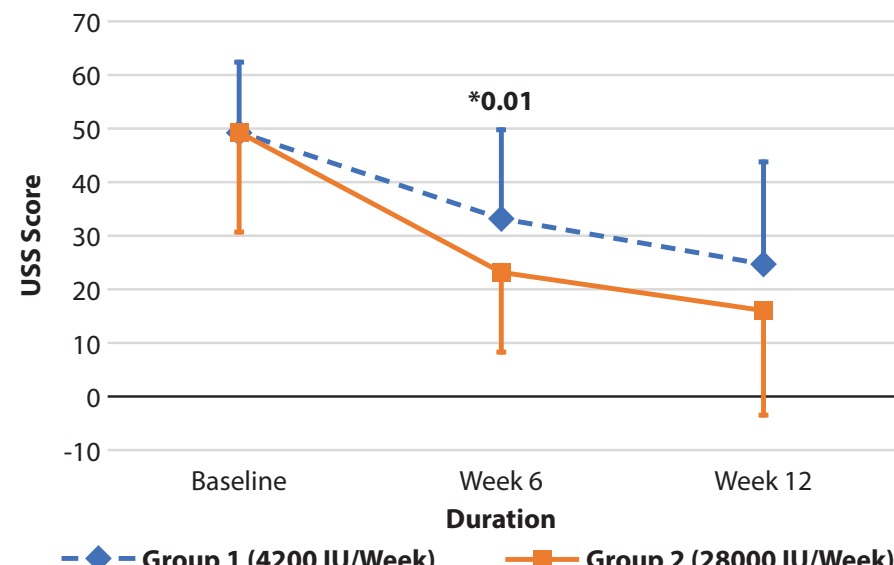

2D

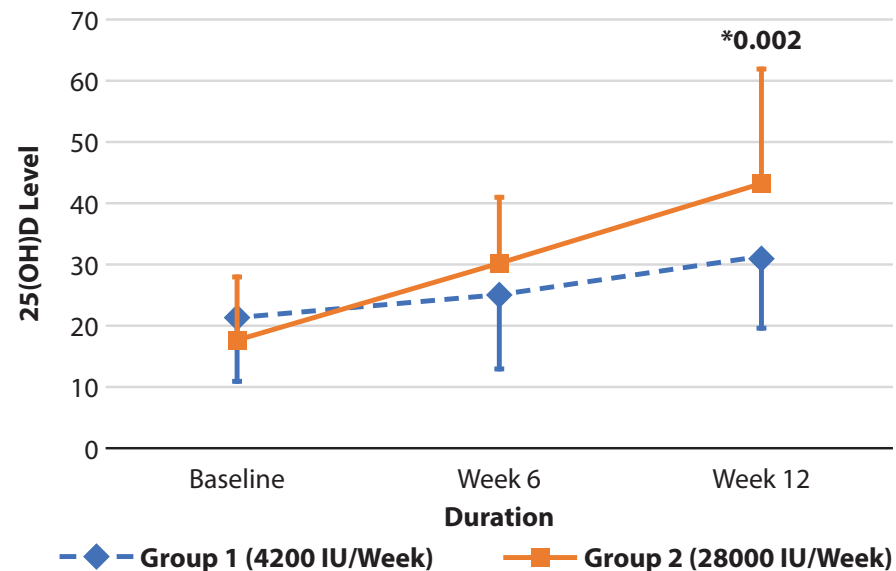

Figure 2. The effect of low dose $(4200 \mathrm{IU} /$ week) and high dose $(28000 \mathrm{IU} /$ week) of vitamin $\mathrm{D}$ on total score of chronic urticaria quality of life (CU- $\left.\mathrm{Q}_{2} \mathrm{oL}\right)(2 \mathrm{~A})$, Total score of urticaria symptom severity (USS) (2B) and Total medication score (2C). 25(OH) D level (2D) is presented at baseline, week 6 and week 12. The significant differences are assigned by ${ }^{*}$. Quality of life score was significantly reduced over the course of study and decrement in group 2 score was significant compared to group 1 at both weeks $6(P=0.005)$ and $12(P=0.007)$. Both groups showed significantly reduced total urticaria severity score and decrement in group 2 score was significant compared to group 1 at week $6(P=0.010)$. Medication score was significantly reduced over the course of study, with no significant difference between groups. 25-hydroxyvitamin D levels were elevated significantly over the course of 12 weeks in both groups; the elevation in group 2 was significantly higher than group 1 at week $12(P=0.002)$

\section{Lab data}

25(OH)D levels

Deficiency in $25(\mathrm{OH}) \mathrm{D}$ level was observed in $65.21 \%$ of the patients $(<20 \mathrm{ng} / \mathrm{L})$. Although at the baseline, the mean level of vitamin D was higher in group 1, the difference with group 2 was not statistically significant. In both groups, the increment in 25(OH)D level was significant at weeks $6(P=$ 0.002 and $P<0.0001$ for groups 1 and 2$)$ and $12(P<0.0001)$, compared to baseline; also, the observed increment at week 6 was statistically significant compared to week $12(P<0.0001)$. The mean level of vitamin $\mathrm{D}$ had significantly increased in each group $(P<0.0001)$; however, the increment was significantly higher in group 2 at week $12(P=0.002)$ (Figure 2D).

\section{Anti TPO level}

High TPO levels were observed in $23.18 \%$ of the patients. Comparing the USS and CU- $\mathrm{Q}_{2} \mathrm{OL}$ total scores in groups with normal and high levels of anti TPO (> $34 \mathrm{IU} / \mathrm{mL})$, no significant difference was recorded at the baseline and also weeks 6 and 12 between groups (Table S1).

\section{ASST test}

Intradermal ASST test was positive in $37.68 \%$ of the patients. Comparing the USS and CU- $\mathrm{Q}_{2} \mathrm{oL}$ total scores in groups with positive and negative ASST test, no significant difference was observed at the baseline and also at weeks 6 and 12 between groups (Table S2).

\section{Angioedema}

The history of angioedema was recorded in $68.11 \%$ of the patients. The total CU- $\mathrm{Q}_{2} \mathrm{OL}$ and USS scores were compared between groups with and without angioedema. Although at the baseline, the total CU- $\mathrm{Q}_{2} \mathrm{oL}$ and USS scores were significantly higher in patients with angioedema, $(P=0.002, P=0.003)$; 
Table S1. Total score of urticarial symptom severity (USS) and chronic urticarial quality of life (CU- $\left.\mathrm{Q}_{2} \mathrm{oL}\right)$ in groups one and two, in patients with anti TPO positive and negative responses

\begin{tabular}{|c|c|c|c|c|c|c|c|}
\hline \multirow[t]{2}{*}{ Questionnaire } & \multirow[t]{2}{*}{ Time } & \multicolumn{2}{|c|}{$\begin{array}{l}\text { Low dose vitamin D treatment group } \\
\text { (4200 IU/week), } \mathrm{n}=35 \\
\text { Mean total score of questionnaire }\end{array}$} & \multirow[t]{2}{*}{$P$-value } & \multicolumn{2}{|c|}{$\begin{array}{l}\text { High dose vitamin D treatment } \\
\text { group ( } 28000 \text { IU/week), } \mathbf{n}=34 \\
\text { Mean total score of questionnaire }\end{array}$} & \multirow[t]{2}{*}{$P$-value } \\
\hline & & $\begin{array}{c}\text { Anti TPO + } \\
\quad(\mathbf{n}=7)\end{array}$ & $\begin{array}{l}\text { Anti TPO - } \\
\quad(n=28)\end{array}$ & & $\begin{array}{c}\text { Anti TPO + } \\
\quad(\mathbf{n}=9)\end{array}$ & $\begin{array}{l}\text { Anti TPO - } \\
\quad(n=25)\end{array}$ & \\
\hline \multirow[t]{3}{*}{$\mathrm{CU}-\mathrm{Q}_{2} \mathrm{oL}$} & Baseline & $75.00 \pm 14.1$ & $66.10 \pm 18.9$ & $0.255^{\mathrm{a}}$ & $61.77 \pm 21.3$ & $59.44 \pm 21.2$ & $0.780^{\mathrm{a}}$ \\
\hline & Week 6 & $61.00 \pm 12.9$ & $53.92 \pm 21.9$ & $0.422^{\mathrm{a}}$ & $36.44 \pm 15.5$ & $43.76 \pm 19.2$ & $0.314^{\mathrm{a}}$ \\
\hline & Week 12 & $49.85 \pm 14.4$ & $46.39 \pm 23.9$ & $0.719^{\mathrm{a}}$ & $29.66 \pm 8.9$ & $35.88 \pm 16.7$ & $0.301^{\mathrm{a}}$ \\
\hline \multirow[t]{3}{*}{ USS } & Baseline & $52.85 \pm 10.0$ & $48.10 \pm 14.3$ & $0.417^{\mathrm{a}}$ & $52.22 \pm 26.6$ & $48.20 \pm 15.5$ & $0.580^{\mathrm{a}}$ \\
\hline & Week 6 & $36.28 \pm 11.7$ & $32.66 \pm 17.7$ & $0.613^{\mathrm{a}}$ & $20.44 \pm 13.1$ & $24.32 \pm 15.8$ & $0.516^{\mathrm{b}}$ \\
\hline & Week 12 & $25.42 \pm 13.8$ & $24.26 \pm 20.5$ & $0.889^{b}$ & $15.90 \pm 25.2$ & $15.98 \pm 17.7$ & $0.996^{\mathrm{b}}$ \\
\hline
\end{tabular}

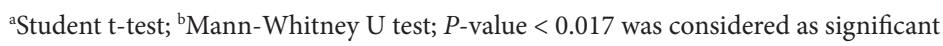

Table S2. Total score of urticarial symptom severity (USS) and chronic urticarial quality of life (CU- $\mathbf{Q}_{2}$ oL) in groups one and two, in patients with ASST positive and negative responses

\begin{tabular}{|c|c|c|c|c|c|c|c|}
\hline \multirow[t]{2}{*}{ Questionnaire } & \multirow[t]{2}{*}{ Time } & \multicolumn{2}{|c|}{$\begin{array}{l}\text { Low dose vitamin D treatment group } \\
\text { (4200 IU/week), } n=35 \\
\text { Mean total score of questionnaire }\end{array}$} & \multirow[t]{2}{*}{$P$-value } & \multicolumn{2}{|c|}{$\begin{array}{l}\text { High dose vitamin D treatment } \\
\text { group ( } 28000 \mathrm{IU} / \text { week), } \mathrm{n}=34 \\
\text { Mean total score of questionnaire }\end{array}$} & \multirow[t]{2}{*}{$P$-value } \\
\hline & & $\begin{array}{l}\text { ASST + } \\
(n=12)\end{array}$ & $\begin{array}{l}\text { ASST - } \\
(n=23)\end{array}$ & & $\begin{array}{l}\text { ASST }+ \\
(n=14)\end{array}$ & $\begin{array}{l}\text { ASST - } \\
(n=20)\end{array}$ & \\
\hline \multirow[t]{3}{*}{$\mathrm{CU}-\mathrm{Q}_{2} \mathrm{oL}$} & Baseline & $72.58 \pm 19.2$ & $65.80 \pm 18.4$ & $0.326^{\mathrm{a}}$ & $62.85 \pm 21.2$ & $58.10 \pm 21.2$ & $0.525^{\mathrm{a}}$ \\
\hline & Week 6 & $55.25 \pm 18.4$ & $55.47 \pm 22.9$ & $0.977^{\mathrm{a}}$ & $37.64 \pm 13.7$ & $44.75 \pm 20.9$ & $0.274^{\mathrm{a}}$ \\
\hline & Week 12 & $44.25 \pm 18.9$ & $49.28 \pm 24.7$ & $0.547^{\mathrm{a}}$ & $31.21 \pm 13.4$ & $36.35 \pm 16.3$ & $0.341^{\mathrm{a}}$ \\
\hline \multirow[t]{3}{*}{ USS } & Baseline & $51.16 \pm 17.3$ & $47.95 \pm 11.9$ & $0.534^{\mathrm{a}}$ & $51.35 \pm 14.8$ & $47.80 \pm 21.2$ & $0.594^{\mathrm{a}}$ \\
\hline & Week 6 & $33.08 \pm 19.9$ & $33.78 \pm 15.7$ & $0.912^{\mathrm{b}}$ & $20.14 \pm 10.7$ & $25.50 \pm 17.3$ & $0.314^{\mathrm{b}}$ \\
\hline & Week 12 & $22.16 \pm 21.6$ & $26.11 \pm 18.5$ & $0.584^{\mathrm{b}}$ & $15.60 \pm 25.3$ & $16.22 \pm 15.0$ & $0.930^{\mathrm{b}}$ \\
\hline
\end{tabular}

aStudent t-test; ${ }^{\mathrm{b} M a n n-W h i t n e y ~} \mathrm{U}$ test; $P$-value $<0.017$ was considered as significant

Table S3. Total score of urticarial symptom severity (USS) and chronic urticarial quality of life (CU-Q $\left.\mathbf{Q}_{2} \mathrm{oL}\right)$ in groups one and two, in patients with and without angioedema

\begin{tabular}{|c|c|c|c|c|c|c|c|}
\hline \multirow{2}{*}{ Questionnaire } & \multirow{2}{*}{ Time } & \multicolumn{2}{|c|}{$\begin{array}{l}\text { Low dose vitamin D treatment group } \\
\text { (4200 IU/week), } \mathrm{n}=35 \\
\text { Mean total score of questionnaire }\end{array}$} & \multirow{2}{*}{$P$-value } & \multicolumn{2}{|c|}{$\begin{array}{l}\text { High dose vitamin D treatment } \\
\text { group ( } 28000 \text { IU/week), } n=34 \\
\text { Mean total score of questionnaire }\end{array}$} & \multirow{2}{*}{$P$-value } \\
\hline & & $\begin{array}{l}\text { Angioedema }+ \\
\quad(n=25)\end{array}$ & $\begin{array}{l}\text { Angioedema - } \\
\qquad(\mathrm{n}=10)\end{array}$ & & $\begin{array}{l}\text { Angioedema }+ \\
\quad(\mathbf{n}=22)\end{array}$ & $\begin{array}{l}\text { Angioedema - } \\
\quad(\mathrm{n}=12)\end{array}$ & \\
\hline \multirow[t]{3}{*}{$\mathrm{CU}-\mathrm{Q}_{2} \mathrm{oL}$} & Baseline & $72.24 \pm 16.6$ & $57.00 \pm 18.4$ & $0.023^{\mathrm{a}}$ & $68.04 \pm 17.2$ & $45.41 \pm 20.0$ & $0.002^{\mathrm{a} *}$ \\
\hline & Week 6 & $58.08 \pm 21.4$ & $48.50 \pm 16.7$ & $0.216^{\mathrm{a}}$ & $45.18 \pm 17.2$ & $35.66 \pm 19.5$ & $0.153^{\mathrm{b}}$ \\
\hline & Week 12 & $49.28 \pm 23.2$ & $41.60 \pm 19.5$ & $0.364^{\mathrm{a}}$ & $35.95 \pm 14.7$ & $31.08 \pm 16.2$ & $0.381^{\mathrm{b}}$ \\
\hline \multirow[t]{3}{*}{ USS } & Baseline & $52.68 \pm 13.8$ & $40.00 \pm 7.8$ & $0.011^{a \star}$ & $56.04 \pm 16.2$ & $36.83 \pm 16.9$ & $0.003^{\mathrm{a} *}$ \\
\hline & Week 6 & $36.92 \pm 17.8$ & $24.55 \pm 8.6$ & $0.045^{\mathrm{a}}$ & $25.72 \pm 14.8$ & $18.80 \pm 14.9$ & $0.206^{\mathrm{b}}$ \\
\hline & Week 12 & $27.92 \pm 20.5$ & $15.9 \pm 12.4$ & $0.097^{\mathrm{b}}$ & $18.80 \pm 21.6$ & $11.90 \pm 15.1$ & $0.381^{\mathrm{b}}$ \\
\hline
\end{tabular}

${ }^{\text {aStudent }}$-test; ${ }^{\mathrm{b}} \mathrm{Mann}$-Whitney $\mathrm{U}$ test; $P$-value $<0.017$ was considered as significant 
no significant difference was observed in USS and QoL score between groups with or without angioedema at weeks 6 and 12 (Table S3).

\section{Discussion}

It was reported that chronic urticaria results in considerable socioeconomic burden. ${ }^{8}$ The mainstay of CU therapy is symptom relief and not disease modifying. Recent researches on urticaria have focused on the underlying immune mechanisms, the involved mediators and mast cell activation pathways; proposing the auto immunity pathways in urticaria pathogenesis. ${ }^{31}$ Evaluation of vitamin D, with immunomodulatory effects, was considered in CU patients in the present work.

In the present study, in line with a meta-analysis by Tuchinda et al., ${ }^{32}$ vitamin $\mathrm{D}$ deficiency was significant in CU patients. Based on Table 1, 86.95\% of the patients were observed with vitamin $\mathrm{D}$ insufficiency/deficiency. Based on the results, it was observed that vitamin D supplementation in CU patients resulted in the reduction of clinical symptoms (USS scores), reduction of medication score, and improvement in QoL (reduction of $\mathrm{CU}-\mathrm{Q}_{2} \mathrm{oL}$ score). Although these effects were observed in both groups, group 2 patients who received higher dose of vitamin D (28000 IU/week) were significantly improved compared to group 1 (Figure 2A-C). CU-Q 2 oL score was significantly different between the two groups in weeks 6 and 12; however, the significant difference in USS was only observed in week 6 . This might be due to the differences in USS and $\mathrm{CU}-\mathrm{Q}_{2} \mathrm{OL}$ questionnaires criteria. Reduced doses of allergy medications were also recorded; however, no significant differences were observed between groups.

The involvement of autoimmunity mechanisms in CU pathogenesis and the association of CU with positive ASST test $^{33}$ and high levels of anti TPO antibody were reported in previous studies. ${ }^{4}$ However, in the present work, positive ASST test and the existence of anti TPO antibodies were not associated with the severity of the disease. In addition, no significant difference was observed in vitamin $\mathrm{D}$ effectiveness.

In the present observation, the frequency of angioedema was higher than previous studies at baseline $(68.11 \%$ (Table S3) vs. $40 \%) .{ }^{1}$ Although patients with angioedema presented with higher USS and CU- $\mathrm{Q}_{2} \mathrm{OL}$ scores at the baseline, no significant difference was observed in vitamin $\mathrm{D}$ effectiveness.

In the study by Tuchinda et al., ${ }^{32}$ adjunctive therapy with higher doses of vitamin $\mathrm{D}_{3}$ for 4-12 weeks (at least 28000 IU/ week) for patients with vitamin $\mathrm{D}$ deficiency was suggested. The recommended dose for vitamin $\mathrm{D}_{2}$ is $140000 \mathrm{IU} /$ week (for 6 weeks). The results of the present randomized clinical study were in accordance with other studies, which reported the effects of vitamin D on the reduction of CU symptoms. In the study by Goetz et al., ${ }^{34} 63$ patients with idiopathic skin disorders (rash, urticarial, angioedema) were followed, of which $90 \%$ had low levels of vitamin $\mathrm{D}(<32 \mathrm{ng} / \mathrm{mL})$. Following the application of $50000 \mathrm{IU}$ vitamin D/week over 8-12 weeks, the symptoms were reduced in $70 \%$ of the patients. In the study by Boonpiyathad et al. ${ }^{23}$ (20000 IU/day of vitamin $\mathrm{D}_{2}, 6$ weeks) and Oguz Topal et al., ${ }^{24}$ (300000 IU/month of vitamin $\mathrm{D}_{3}$ for 3 months) the urticarial activity score (UAS) and dermatology life quality index (DLQI) were reduced significantly following vitamin D supplementation.
This study was compared with the study by Rorie et al. in which the effect of vitamin D (600 IU/day and $4000 \mathrm{IU} /$ day) for CU patients was determined. ${ }^{26}$ The severity of clinical symptoms was reduced and QoL has improved; however, no significant change was observed in the required dose of allergy medications. In the group receiving low dose of vitamin $\mathrm{D}$ (600 IU/day), the recorded level of vitamin D was not elevated significantly at the end of the study, compared to its baseline level. On the contrary, in our study the vitamin D level had increased, using low dose of vitamin D (4000 IU/week). This might be due to the difference in the baseline level of vitamin $\mathrm{D}$, which was lower in both groups of the present study. Due to the nonlinear kinetic of vitamin $\mathrm{D}$ elevation, the elevation slope in the patients with lower level of vitamin $\mathrm{D}$ would be higher. ${ }^{35}$ Another difference is higher mean BMI in the study by Rorie et al. ${ }^{26}$ (Table 1). Patients with higher BMI require higher dosage of vitamin D. ${ }^{29}$

There are confounding variables in vitamin $\mathrm{D}$ level such as ethnicity, geographical region and cultural beliefs which affect sunlight exposure and the amount of produced vitamin D. Difference of melanin pigmentations is another factor. This study was conducted in south Iran with specific cultural and geographical background.

There are some limitations to this study. The number of subjects was limited and it was not a placebo-controlled study. To find out whether vitamin D add-on therapy is efficient to improve CU symptoms, further placebo-controlled studies with larger sample size in various cultural and geographical conditions are warranted.

\section{Conclusion}

Based on this study, it might be concluded that using high dose of vitamin D (28000 IU/week) as add-on therapy results in the reduction of $\mathrm{CU}$ symptoms severity and the required doses of allergy medications.

\section{Acknowledgments}

The authors would like to thank the staff of tertiary center of immunology and allergy, Ms. Kazemi and Ms. Firouzabadi. The authors wish to thank Mr. H. Argasi at the Research Consultation Center (RCC) of Shiraz University of Medical Sciences for his invaluable assistance in editing this manuscript. This study was supported by Shiraz University of Medical Sciences, Shiraz, Iran. The authors declare no conflict of interest. SHN, SA, FM, HE, NE contributed to the study conception; HE and FM supervised the study; SHN and SA designed the study and contributed to data interpretation and critical revision of the manuscript; FM carried out the experiment, analyzed data and drafted the manuscript; HE and NE were contributed in data analysis and manuscript preparation. All authors have read and approved the manuscript.

\section{References}

1. Kaplan AP. Chronic urticaria: pathogenesis and treatmentl. J Allergy Clin Immunol. 2004;114:465-74

2. Maurer M, Zuberbier T, Siebenhaar F, Krause K. Chronic urticaria-What does the new guideline tell us? JDDG. 2018;16:584-93.

3. Powell R, Leech S, Till S, Huber P, Nasser S, Clark A. BSACI guideline for the management of chronic urticaria and angioedemal. Clin Exp Allergy. 2015;45:547-65. 
4. Ulambayar B, Park HS. Anti-TPO IgE Autoantibody in Chronic Urticaria: Is It Clinically Relevant? Allergy Asthma Immunol Res. 2019;11:1-3.

5. Elazab S, F Hessam W. The Effect of Autologous Serum Therapy in Chronic Spontaneous Urticaria Depends on Autologous Serum Skin Test Positivity. Egypt J Immunol. 2017; 165-72.

6. Radonjic-Hoesli S, Hofmeier KS, Micaletto S, Schmid-Grendelmeier P, Bircher A, Simon D. Urticaria and angioedema: an update on classification and pathogenesisl. Clin Rev Allergy Immunol. 2018;54:88-101.

7. Altrichter S, Peter HJ, Pisarevskaja D, Metz M, Martus P, Maurer M. IgE mediated autoallergy against thyroid peroxidase-a novel pathomechanism of chronic spontaneous urticaria? PloS One. 2011;6:e14794.

8. Zuberbier T, Aberer W, Asero R, Latiff AA, Baker D, Ballmer-Weber $\mathrm{B}$, et al. The EAACI/GA ${ }^{2} \mathrm{LEN} / \mathrm{EDF} / \mathrm{WAO}$ guideline for the definition, classification, diagnosis and management of urticarial. Allergy. 2018; 73:1393-414.

9. Bernstein JA, Lang DM, Khan DA, Craig T, Dreyfus D, Hsieh F, et al. The diagnosis and management of acute and chronic urticaria: 2014 updatel. J Allergy Clin Immunol. 2014;133:1270-7.

10. Marrouche N, Grattan C. Update and insights into treatment options for chronic spontaneous urticarial. Expert Rev Clin Immunol. 2014;10: 397-403.

11. Muehleisen B, Gallo RL. Vitamin D in allergic disease: shedding light on a complex probleml. J Allergy Clin Immunol. 2013;131:324-29.

12. Alyasin S, Momen T, Kashef S, Alipour A, Amin R. The relationship between serum 25-hydroxyvitamin D levels and asthma in childrenl. Allergy Asthma Immunol Res. 2011;3:251-5.

13. Arshi S, Fallahpour M, Nabavi M, Bemanian MH, Javad-Mousavi SA, Nojomi M, et al. The effects of vitamin D supplementation on airway functions in mild to moderate persistent asthmal. Ann Allergy Asthma Immunol. 2014;113:404-9.

14. Peroni D, Piacentini G, Cametti E, Chinellato I, Boner A. Correlation between serum 25-hydroxyvitamin D levels and severity of atopic dermatitis in childrenl. Br J Dermatol. 2011;164:1078-82.

15. Dogru M. Is vitamin D level associated with the natural course of atopic dermatitis? Allergol Immunopathol. 2018;46:546-51.

16. Grzanka A, Machura E, Mazur B, Misiolek M, Jochem J, Kasperski J, et al. Relationship between vitamin D status and the inflammatory state in patients with chronic spontaneous urticarial. J Inflammation. 2014;11:1-2.

17. Quirk SK, Rainwater E, Shure AK, Agrawal DK. Vitamin D in atopic dermatitis, chronic urticaria and allergic contact dermatitisl. Expert Rev Clin Immunol. 2016;12:839-47.

18. Chu C-C, Ali N, Karagiannis P, Di Meglio P, Skowera A, Napolitano L, et al. Resident CD141 (BDCA3)+ dendritic cells in human skin produce IL-10 and induce regulatory $\mathrm{T}$ cells that suppress skin inflammationl. J Exp Med. 2012;209:935-45

19. Bunyavanich S, Rifas-Shiman SL, Platts-Mills TA, Workman L, Sordillo JE, Camargo Jr CA, et al. Prenatal, perinatal, and childhood vitamin D exposure and their association with childhood allergic rhinitis and allergic sensitizationl. J Allergy Clin Immunol. 2016;137:1063-70.

20. Thorp WA, Goldner W, Meza J, Poole JA. Reduced vitamin D levels in adult subjects with chronic urticarial. J Allergy Clin Immunol. 2010;126:413.
21. Chandrashekar L, Rajappa M, Munisamy M, Ananthanarayanan PH, Thappa DM, Arumugam B. 25-Hydroxy vitamin D levels in chronic urticaria and its correlation with disease severity from a tertiary care centre in South Indial. Clin Chem Lab Med. 2014;52:e115-18.

22. Woo YR, Jung KE, Koo DW, Lee JS. Vitamin D as a marker for disease severity in chronic urticaria and its possible role in pathogenesisl. Ann Dermatol. 2015;27:423-30.

23. Boonpiyathad T, Pradubpongsa P, Sangasapaviriya A. Vitamin D supplements improve urticaria symptoms and quality of life in chronic spontaneous urticaria patients: a prospective case-control study. Dermatoendocrinol. 2014;6(1): e29727.

24. Oguz Topal I, Kocaturk E, Gungor S, Durmuscan M, Sucu V, Yildırmak $S$. Does replacement of vitamin $\mathrm{D}$ reduce the symptom scores and improve quality of life in patients with chronic urticaria? J Dermatol Treat. 2016;27:163-6.

25. Ross AC, Manson JE, Abrams SA, Aloia JF, Brannon PM, Clinton SK, et al. The 2011 report on dietary reference intakes for calcium and vitamin D from the Institute of Medicine: what clinicians need to knowl. J Clin Endocrinol Metab. 2011;96:53-8.

26. Rorie A, Goldner WS, Lyden E, Poole JA. Beneficial role for supplemental vitamin D3 treatment in chronic urticaria: a randomized studyl. Ann Allergy Asthma Immunol. 2014;112:376-82.

27. Jariwala SP, Moday H, De Asis ML, Fodeman J, Hudes G, De Vos G, et al. The Urticaria Severity Score: a sensitive questionnaire/index for monitoring response to therapy in patients with chronic urticarial. Ann Allergy Asthma Immunol. 2009;102:475-82.

28. Tavakol M, Mohammadinejad P, Baiardini I, Braido F, Gharagozlou M Aghamohammadi A, et al. The persian version of the chronic urticaria quality of life questionnaire: factor analysis, validation, and initial clinical findingsl. Iran J Allergy Asthma Immunol. 2014;13:278-85.

29. Holick MF, Binkley NC, Bischoff-Ferrari HA, Gordon CM, Hanley DA, Heaney RP, et al. Evaluation, treatment, and prevention of vitamin D deficiency: an Endocrine Society clinical practice guidelinel. J Clin Endocrinol Metab. 2011;96:1911-30.

30. Sabroe R, Grattan C, Francis D, Barr R, Kobza BA, Greaves M. The autologous serum skin test: a screening test for autoantibodies in chronic idiopathic urticarial. Br J Dermatol. 1999;140:446-52.

31. Antia C, Baquerizo K, Korman A, Bernstein JA, Alikhan A. Urticaria: A comprehensive review: Epidemiology, diagnosis, and work-upl. J Am Acad Dermatol. 2018;79:599-614

32. Tuchinda P, Kulthanan K, Chularojanamontri L, Arunkajohnsak S Sriussadaporn S. Relationship between vitamin D and chronic spontaneous urticaria: a systematic reviewl. Clin. Transl. Allergy. 2018;8:51.

33. Alyasin S, Karimi AA, Amiri A, Ehsaei MJ, Ghaffarpasand F. Correlation between clinical findings and results of autologous serum skin test in patients with chronic idiopathic urticarial. Allergy Asthma Clin Immunol. 2011;7:1

34. Goetz DW. Idiopathic itch, rash, and urticaria/angioedema merit serum vitamin D evaluation: a descriptive case seriesl. W V Med J. 2011;107:14-21.

35. Cannell JJ, Hollis BW. Use of vitamin D in clinical practicel. Altern Med Rev. 2008;13:6-20. 